\title{
COVID-19 E AS REGIÕES ADMINISTRATIVAS DO DISTRITO FEDERAL: A RELAÇÃO ENTRE AS MORTES CAUSADAS PELA PANDEMIA E O DIREITO FUNDAMENTAL À MORADIA ADEQUADA
}

\author{
Júlia Eduarda Dias Vaz - CEUB, PIC/PIBIC COVID-19 CEUB, aluna bolsista \\ juhvaz1310@sempreceub.com \\ Anna Luiza de Castro Gianasi - CEUB, professora orientadora \\ anna.gianasi@ceub.edu.br
}

A notoriedade do direito à moradia adquire proporções significativas no período de pandemia de covid-19, tendo em vista que uma das maiores recomendações da Organização Mundial da Saúde aponta para ficar em casa, lavar as mãos, usar máscaras e observar o distanciamento social. Conforme esse contexto, a presente pesquisa empírica objetiva responder se há ou não correlação entre o direito à moradia e a maior taxa de mortalidade por covid-19 nas Regiões Administrativas (RA) do Distrito Federal (DF). Para isso, a partir da análise documental, levantaram-se os dados de mortalidade por coronavírus em cada RA do $D F$, relacionando-os com o déficit habitacional. Ademais, analisaram-se qualitativamente e quantitativamente as recomendações técnicas da Organização Mundial da Saúde e da Secretaria da Saúde do DF a partir dos dados disponíveis em seus sites oficiais, no período de 12 de março a outubro de 2020, a fim de verificar a importância da moradia adequada no período pandêmico. Foi feita análise quantitativa das políticas públicas relacionadas à moradia no mesmo período, elaboradas por secretarias do Governo do Distrito Federal, acessando a aba "notícias" do endereço eletrônico de cada uma delas, para verificar se houve garantia desse direito. Para analisar os dados, utilizou-se como marco teórico a base de autores de direitos fundamentais, direitos humanos, direito urbanístico, sociólogos, entre outros. Por fim, conclui-se que o coronavírus se revela de maneira desigual, no território, tendo maior taxa de mortalidades nas RA com maior déficit habitacional. A despeito das políticas públicas relativas à moradia no período de pandemia, percebe-se que não foram capazes de barrar a taxa de mortalidade, pois se comportam de forma diferente quando os dados são avaliados na geografia urbana, entre as regiões centrais e as periféricas. A partir do exposto, foi possível criar subsídios para constatar a hipótese de que há ligação entre as taxas de mortalidade por covid-19 e o direito à moradia nas regiões periféricas do Distrito Federal, além de verificar a tendência no território da capital que é a desigualdade regional entre as RA e a constatação da ideia de centro e periferia, como aquele detentor de maiores garantias e essa marcada pela relativização de direitos, ou seja, o facismo social, que encontra, no coronavírus, terreno fértil para exercer seu poder de morte ou o necropoder. Essa constatação é de suma importância para o enfrentamento da pandemia, uma vez que o resultado é subsídio relevante para formular políticas públicas eficientes e territorializadas, com o objetivo de possibilitar prestações efetivas no que tange o direito à moradia nas áreas periféricas, cujo resultado, entre outros, seja também reduzir a mortalidade por covid-19 no entorno do Distrito Federal.

Palavras-Chave: direito à moradia; covid-19; taxa de mortalidade; regiões administrativas do Distrito Federal; política pública. 